\title{
The Effect of Beta-Alanine Supplementation on First and Second Ventilatory Threshold of Male Swimmers
}

\author{
Ali Arjmandpanah Eilaki ${ }^{1}$, Mohammad Esmaeil Afzalpour ${ }^{1}$, Reza Bagheri ${ }^{2}$, Mohammad Mosaferi Ziaaldini ${ }^{2 *}$ \\ 1- Faculty of Sport Sciences, University of Birjand, Iran. \\ 2- Faculty of Sport Sciences, Ferdowsi University of Mashhad, Iran.
}

\section{A B S T R A C T}

Background and Objectives: One of the important factors in comparative athletes, especially swimmers, is respiratory function and respiration regulation during training and competition. The purpose of this study was to investigate the effect of 14 days of beta-alanine supplementation on first and second ventilatory threshold of the male swimmers.

Materials and Methods: Fourteen male swimmers were randomly divided into two groups, including supplementation (S) (age, $30.67 \pm 6.34$ years and BMI, $23.71 \pm 2.28 \mathrm{~kg} / \mathrm{m}^{2}$ ) and placebo (P) (age, $32.63 \pm 10.26$ years and BMI, $25.16 \pm$ $2.51 \mathrm{~kg} / \mathrm{m}^{2}$ ). The supplementation group took beta-alanine $2-3 \mathrm{~g} \cdot \mathrm{day}^{-1}$ in first week and 4-6 $\mathrm{g} \cdot \mathrm{day}^{-1}$ in second week whereas the control group took dextrose for two weeks instead but in same way. The respiratory indices of subjects were measured using cardio pulmonary exercise testing. Independent sample $t$ test and paired-sample $t$ test was used to compare the outcomes between and within groups respectively. The significance level was assumed as $95 \%$ for all cases $(\mathrm{p}<0.05)$.

Results: The results showed that $\beta$-alanine supplementation increased first and second ventilatory threshold $\left(\mathrm{VT}_{1}\right.$ and $\mathrm{VT}_{2}$ respectively) in $\mathrm{S}$ group $(\mathrm{p} \leq 0.05)$. However, there was no significant difference between groups for $\mathrm{VT}_{2}$.

Conclusions: Two weeks of beta-alanine supplementation with a dose of 2-6 grams per day provides a sufficient stimulus to improve the competitive ability of swimmers.

Keywords: Beta-alanine, Respiratory indexes, Swimmers performance, First ventilatory threshold, Second ventilatory threshold

\section{Introduction}

One of the important factors in comparative athletes, especially swimmers, is respiratory function and respiration regulation during training and competition. During moderate to high-intensity exercises, hydrogen ions begin to accumulate and result in the decrease of $\mathrm{pH}$ in the cell and ultimately affect muscle function. Further reliance on glycogen as the primary energy system increases lactic acid production and hydrogen ion, resulting in a further reduction of intracellular $\mathrm{pH}$. Reducing $\mathrm{pH}$ in the cell, increases fatigue in muscle activity and electromyography oscillation. Therefore, a decrease of intracellular $\mathrm{pH}$ should be prevented (1).

The first increase in blood lactate (lactate threshold) without elevation of the $\mathrm{pH}$ level is the first indication of the onset of buffering in high-intensity sports. The lactic acid produced in the active muscle is generally neutralized by bicarbonate ion. In light of this, three physiological phases of gas changes can be identified during the rapid progressive exercise test. Phase 1, when production of $\mathrm{CO}_{2} \quad\left(\mathrm{VCO}_{2}\right)$ is essentially from oxidative metabolism, and Phase 2 (isocapnic buffering) where alveolar ventilation (Ve) increases in response to rising $\mathrm{VCO}_{2}$ buffering, by adjusting the $\mathrm{CO}_{2}$ and phase 3 , Where compensatory respiration occurs for metabolic acidosis by decreasing the $\mathrm{CO}_{2}$ partial pressure (hypocapnic hyperventilation). The points that limit these three phases are called ventilatory thresholds (2).

The short period of isocapnic buffering may vary among subjects and reflects the status of the body's general buffering capacity toward exercise-induced metabolic acidosis, especially in increased lactate accumulation. The onset of hyperventilation might 
reflect the furthest point at which the body's metabolic systems attempt to compensate for metabolic acidosis (3).

Beta-alanine is a non-essential amino acid that can be synthesized in the liver and obtained from diet, particularly from white meat (poultry and fish) and red meat. Endogenous synthesis of Beta-alanine derives from degradation of the pyrimidines thymine, cytosine and uracil and its transport to skeletal muscle is sodium- and chloride- dependent. The entry of Beta-alanine to the cells may be affected by similar structure compounds (glycine, taurine, gammaaminobutyric acid) that compete for the same transporter. It is in the skeletal muscle that BA plays its most important role, as an intermediate and limiting factor for carnosine synthesis. Carnosine is a dipeptide, responsible for reducing fatigue and buffering muscle acidosis (4).

The supplementation of beta-alanine can lead to increased muscle carnosine in both slow and fast twitch muscle fibers, which can improve the muscle's ability to neutralize protons and postpone muscular fatigue (5).

The results of a study done by Saunders et al (2017) demonstrated that 24-weeks of beta-alanine supplementation increased muscle carnosine content and improved high-intensity cycling capacity in active males (6).

Brisola et al (2016) investigated the effect of four weeks of beta-alanine supplementation on repeated sprint ability in water polo players. Twenty-two male water polo players were divided randomly into placebo and beta-alanine groups. Before and after the supplementation period ( 28 days), the athletes performed two specific repeated sprint ability tests interspaced by a 30-minute swimming test. Participants received $4.8 \mathrm{~g}$ per day of the supplement (dextrose or beta-alanine) on the first 10 days and 6.4 g per day on the final 18 days. The result showed that there was no significant group-time interaction for any of the variables. However, it was concluded that four weeks of beta-alanine supplementation had a beneficial effect in the first set of repeated sprint ability tests and a possible beneficial effect for the worst time in the second set performed in a specific protocol in water polo players (7).

Another study showed that a 28-day supplementation with 6.4 g.day $^{-1}$ of beta-alanine supplementation may prove to be beneficial in to reduce the effect of fatigue on muscle twitch contraction (8).

Possible beneficial effects of beta-alanine supplementation on the swimming performance has been investigated by Claus et al (2017). In this study, fifteen young water polo players underwent a $200-\mathrm{m}$ swimming performance, repeated-sprint ability test (RSA) with free throw (shooting), and 30-s maximal tethered eggbeater kicks. Participants were randomly allocated into two groups (placebo $\mathrm{x}$ beta-alanine) and supplemented with $6.4 \mathrm{~g} \cdot \mathrm{day}^{-1}$ of beta-alanine or a placebo for six weeks. The result showed that six weeks of beta-alanine supplementation was effective for improving ball velocity shooting in the RSA, maintaining performance in the $30-\mathrm{s}$ test, and providing possibly beneficial effects in the $200-\mathrm{m}$ swimming performance (9).

Other studies also have been investigated the long and short-term effects of beta-alanine supplementation on the athlete's and non-athletes performance $(5,10-13)$. However, little information is available on beta-alanine supplementation on the anaerobic threshold. Therefore, the purpose of this study was to investigate the effect of 14 days betaalanine supplementation on $\mathrm{VT}_{1}$ and $\mathrm{VT}_{2}$ of the male swimmers followed by a single bout of the exhaustive session.

\section{Materials and Methods}

Fourteen amateur male swimmers completed the study and were randomly assigned into the supplement group $(\mathrm{S}, \mathrm{N}=6)$ or the placebo group ( $\mathrm{P}$, $\mathrm{N}=8$ ). All participants were informed of the risks and benefits of participation, and upon agreement, signed consent was collected. The players engaged in the study took part on the same team with at least two years of experience and same daily training participants had not taken any additional dietary supplements 3 months prior to the start of the study.

At first, the subjects warmed up on treadmill (Cosmed K4b2, Italy) for 10 to 15 minutes, according to physical fitness, until the heart rate reached 70$75 \%$ of the heart rate reserve.

Then, the subjects performed at a speed of at least $70-75 \%$ of the heart rate reserve for one minute. Then, every 2 minutes, two kilometers per hour was added to the treadmill speed. The increase in work load continued until the subject got into a state of exhaustion. Gas exchange data were obtained using an automated breath by breath system (Cortex Metalyzer 3B). The instruments were calibrated before each test and the necessary environmental adjustments were made. Ventilatory equivalents for oxygen and carbon dioxide ( $\mathrm{Ve} / \mathrm{Vo} 2$ and $\mathrm{Ve} / \mathrm{Vco} 2$ respectively) were measured from $\mathrm{VO} 2, \mathrm{Vco} 2$, and $\mathrm{Ve}$ data was recorded during the tests.

Determination of the range of isocapnic buffering and hypocapnic hyperventilation

Before and after taking the supplement, the VSlope of the subjects was measured through exercise 
tests. The V-Slope shape is obtained from the ratio of carbon dioxide to volume of oxygen. In this figure, the vertical axis represents the production volume of carbon dioxide and the horizontal axis indicates the volume of gas consumed.

Based on this curve, the aerobic, anaerobic, and exhaustion points were determined and using this, the surface under the curve of the isocapnic buffering and (the distance from the aerobic threshold to the anaerobic threshold) and the hypocapnic hyperventilation (from the aerobic threshold to exhaustion) were calculated.

Supplementation protocol

Participants received either beta-alanine (OLIMP SPORT NUTRITION) or a placebo (Dextrose) for 2 weeks. Both the placebo and $\beta$-alanine were packed in capsules identical in appearance. Participants received 2-3 $\mathrm{g} \cdot \mathrm{day}^{-1}$ in first week and 4-6 $\mathrm{g} \cdot \mathrm{day}^{-1}$ in second week of beta-alanine or a placebo, divided into two daily doses.

Statistical analysis

Data normality was analyzed by the Shapiro-Wilk test. Data are presented as means \pm standard deviation (SD). independent sample $t$ test was used to compare the outcomes between groups (placebo vs. betaalanine) and paired-sample $t$ test as the within group (pre and post). However, if the 95\% confidence interval does not include zero, the mean percent change for that variable can be considered statistically significant $(\mathrm{p} \leq 0.05)$. The statistical analysis was performed using the SPSS software package for Windows version 21.

\section{Results}

The anthropometrical and physiological profile of subjects is shown in Table 1 and 2 .

Table 1. Subject characteristics

\begin{tabular}{lcc}
\hline \multirow{2}{*}{ characterize } & \multicolumn{2}{c}{ Group } \\
& \multicolumn{2}{c}{$\mathrm{M} \pm \mathrm{SD}$} \\
\hline Age (year) & $30.67 \pm 6.34$ & $\mathrm{P}(\mathrm{N}=6)$ \\
Height $(\mathrm{cm})$ & $180 \pm 6.72$ & $32.63 \pm 10.26$ \\
Weight $(\mathrm{kg})$ & $76.53 \pm 9.15$ & $92.63 \pm 9.04$ \\
BMI $\left(\mathrm{kg} \mathrm{/} \mathrm{m}{ }^{2}\right)$ & $23.71 \pm 2.28$ & $25.16 \pm 2.51$ \\
PBF $(\%)$ & $18.88 \pm 6.72$ & $14.68 \pm 4.52$ \\
SMM $(\mathrm{kg})$ & $35.03 \pm 2.38$ & $35.82 \pm 3.68$ \\
BFM $(\mathrm{kg})$ & $14.91 \pm 7.09$ & $14.38 \pm 4.38$ \\
\hline
\end{tabular}

Abbreviations: BMI: Body Mass Index, PBF: Percent Body Fat, SMM: Skeletal Muscle Mass, BFM: Body Fat Mass. P: Placebo, S: Supplementation

The results of Table 3 show that 14 days betaalanine supplementation significantly increased the $\mathrm{VT}_{1}$ in the $\mathrm{S}$ group compared to the pre-test $(\mathrm{P} \leq 0.05)$. However, there was no significant difference between pre-test and post-test in the $\mathrm{VT}_{1}$ of the $\mathrm{P}$ group $(\mathrm{p}=$ 0.273). Also, the increase in the $\mathrm{VT}_{1}$ following 14 days supplementation in the $\mathrm{S}$ group was significantly higher compared to the $P$ group $(\mathrm{p} \leq 0.05)$.

Intra and inter group changes of $\mathrm{VT}_{2}$ of the subjects following the two weeks beta-alanine supplementation are shown in the Table 4 . The results showed that 14 days of beta-alanine supplementation resulted in a significant increase in the $\mathrm{VT}_{2}$ values in the post-test compared to the pre-test in the $\mathrm{S}$ group $(p \leq 0.05)$ however, there was no significant changes in the $\mathrm{P}$ group. Furthermore, no significant difference was observed for the $\mathrm{VT}_{2}$ between $\mathrm{S}$ and $\mathrm{P}$ groups.

Table 2. The physiological variables of subject before (pre-test) and after (post-test) intervention

\begin{tabular}{lccc}
\hline \multicolumn{1}{c}{ Indices } & \multicolumn{3}{c}{ Group } \\
\cline { 2 - 3 } & & $\mathrm{S}(\mathrm{N}=8)$ & $\mathrm{P}(\mathrm{N}=6)$ \\
\hline $\mathrm{VO} 2_{\max }(\mathrm{L} / \mathrm{Min})$ & Pre-test & $3.47 \pm 0.34$ & $3.31 \pm 0.42$ \\
$\mathrm{VO} 2_{\max }(\mathrm{ml} / \mathrm{kg} / \mathrm{min})$ & Post-test & $3.45 \pm 0.33$ & $3.31 \pm 0.42$ \\
& Pre-test & $45.33 \pm 3.26$ & $43 \pm 5.90$ \\
$\mathrm{MHR}($ beats / min) & Post-test & $46 \pm 2.53$ & $43.50 \pm 6.04$ \\
& Pre-test & $170.50 \pm 3.98$ & $167.50 \pm 10.28$ \\
$\mathrm{MRS}(\mathrm{km} / \mathrm{h})$ & Post-test & $170.50 \pm 3.98$ & $168.88 \pm 9.94$ \\
& Pre-test & $6.58 \pm 0.53$ & $6.93 \pm 1.28$ \\
$\mathrm{TDA}$ (second) & Post-test & $6.58 \pm 0.53$ & $6.93 \pm 0.79$ \\
& Pre-test & $710.17 \pm 68.80$ & $712.88 \pm 75.70$ \\
\hline
\end{tabular}

Abbreviations: MHR: Maximum Heart Rate, MRS: Maximum Running Speed, TDA: Total Duration of Activity, P: Placebo, S: Supplementation 
Ali Arjmandpanah Eilaki, et al: Beta- alanine supplementation and ventilatory threshold

Table 3. Intra and inter group changes of swimmer's $\mathrm{VT}_{1}$ flowing by 14 days beta-alanine supplementation.

\begin{tabular}{|c|c|c|c|c|c|c|c|}
\hline \multirow[t]{2}{*}{ Group } & \multicolumn{2}{|c|}{$\begin{array}{c}\mathrm{VT}_{1} \\
\mathrm{M} \pm \mathrm{SD} \\
\end{array}$} & \multicolumn{2}{|c|}{ Intergroup changes } & \multicolumn{3}{|c|}{ Between-group changes } \\
\hline & Pre-test & Post-test & $\mathrm{T}$ & $\mathrm{P}$ value & Difference between pre and post-test & Independent t-test & $\begin{array}{c}\mathrm{P} \\
\text { value }\end{array}$ \\
\hline \multirow[t]{2}{*}{$\mathrm{S}$} & $2.34 \pm 0.32$ & $2.80 \pm 0.54$ & 4.087 & $0.009^{*}$ & $0.45 \pm 0.27$ & & \\
\hline & & & & & & 2.16 & $0.05^{*}$ \\
\hline $\mathrm{P}$ & $2.56 \pm 0.28$ & $2.68 \pm 0.22$ & 1.19 & 0.273 & $0.12 \pm 0.29$ & & \\
\hline
\end{tabular}

*significant difference was set at $\mathrm{P}<0.05$

Table 4. Intra and inter group changes of swimmer's $\mathrm{VT}_{2}$ following by 14 days beta-alanine supplementation.

\begin{tabular}{|c|c|c|c|c|c|c|c|}
\hline \multirow{2}{*}{ Group } & \multicolumn{2}{|c|}{$\begin{array}{c}\mathrm{VT}_{2} \\
\mathrm{M} \pm \mathrm{SD} \\
\end{array}$} & \multicolumn{2}{|c|}{ Intergroup changes } & \multicolumn{3}{|c|}{ Intra-group changes } \\
\hline & Pre-test & Post-test & $\mathrm{T}$ & $P$ value & Difference between pre and post-test & Independent t-test & $\begin{array}{c}\mathrm{P} \\
\text { value }\end{array}$ \\
\hline$S$ & $3.69 \pm 0.35$ & $4.12 \pm 0.56$ & 2.82 & $0.03^{*}$ & $0.43 \pm 0.37$ & \multirow{3}{*}{0.76} & \multirow{3}{*}{0.45} \\
\hline & & & & & & & \\
\hline $\mathrm{P}$ & $3.51 \pm 0.34$ & $3.78 \pm 0.35$ & 1.82 & 0.11 & $0.26 \pm .33$ & & \\
\hline
\end{tabular}

*significant difference was set at $\mathrm{P}<0.05$

\section{Disc ussion}

The results of the present study showed that a short-term beta-alanine supplementation increases $\mathrm{VT}_{1}$. However, beta-alanine supplementation did not have a significant effect on the $\mathrm{VT}_{2}$ of male swimmers compared with the placebo. Between the two points of the first lactate threshold (VT1) and compensatory ventilation threshold, the buffering system begins to work but at the compensatory ventilatory threshold breaks resulted in an increase in hydrogen ion and a decrease in $\mathrm{pH}$ and consequently impaired function of the individual. In this regard, since beta-alanine is a precursor to carnosine, its consumption may have an effect on muscle buffering capacity. In support of this, some studies have reported that improving carnosine is effective in improving intra-muscle buffering capacity. Harris et al., (2006) has shown that 4 weeks of beta-alanine supplementation increases muscle buffering capacity by $12-14 \%$ (14). Also, Trexler et $a l .$, (2015) emphasized the importance of beta-alanine supplementation for improving anaerobic performance (15). These studies argue that physical activity between 60 to 240 seconds increased intra and extracellular hydrogen ion and is one of the voluntary fatigue factors. Based on the analysis of our results, 14 days of beta-alanine supplementation had a significant effect on $\mathrm{VT}_{1}$ of young swimmers. Since the $\mathrm{pH}$ drop occurs first in the muscle cell which is then transmitted to the intermediate tissue and bloodstream, it is evident that the process of coping with the $\mathrm{pH}$ decline first occurs within the muscle cell, which is done by carnosine.

Indeed, the increase in the ventilatory threshold is likely to be partly due to the increased synthesis of carnosine in the muscle which is due to an increase in its main substrate, beta-alanine as in previous studies showed an increase in carnosine synthesis has as a result of beta-alanine supplementation (16). As a result of beta-alanine supplementation, postponement of the onset of lactate accumulation and a sudden increase in Hydrogen ion levels, $\mathrm{VT}_{1}$ occurs at a higher percentage of the maximal oxygen consumed. According to previous studies, beta-alanine supplementation is responsible for the buffering system, carnosine (17), antioxidant role (1), enzyme regulator (18) and calcium control in the sarcoplasmic reticulum.

Based on the other studies, power decrease and muscle function impairedness are due to the sarcoplasmic calcium reduction because of the continuation of muscle contraction and the accumulation of intracellular calcium and its failure to return to the sarcoplasmic reticulum (19). From this perspective, increasing muscle carnosine increases muscle contraction protein function and, as a result, increases the productivity of contractile motor units (18). Obviously, the energy requirement decreases as a result of increasing the efficiency of contractile motor units at a certain intensity; therefore, the 
contribution of glycolysis to this effect is reduced, and the $\mathrm{VT}_{1}$, then lactate threshold occurs in higher intensities.

The result of the present study showed that 14 days of beta-alanine supplementation did not have a significant difference on the $\mathrm{VT}_{2}$ between $\mathrm{S}$ and $\mathrm{P}$ groups, although changes in the $\mathrm{S}$ group were significant. The $\mathrm{VT}_{2}$ has been less well known. A remarkable point in relation to the $\mathrm{VT}_{2}$ is that the body's overall buffering system can affect it, however, the extent of its effectiveness from body buffering systems is not well understood. In other words, the contribution of each of the body buffering systems is not well known (20). Accordingly, intracellular levels of carnosine appear to affect the second respiratory threshold, but the effect of other factors is more. Since the threshold of second ventilatory is a multifactor variable, in addition to the buffering system, there are other factors affecting it, which is not well known and requires more research in this regard.

\section{Conclusion}

The results of this study showed that 14 days of beta-alanine supplementation causes significant changes in the $\mathrm{VT}_{1}$ but did not reach a significant effect on the $\mathrm{VT}_{2}$ of young male swimmers. This means that two weeks of beta-alanine supplementation with a given dose can provide enough stimuli to improve the swimmers' competitive performance.

\section{Financial disclosure}

The authors declared no financial interest.

\section{Funding/Support}

The study did not receive any financial support.

\section{References}

1. Culbertson JY, Kreider RB, Greenwood M, Cooke M. Effects of beta-alanine on muscle carnosine and exercise performance: a review of the current literature. Nutrients. 2010;2(1):75-98.

2. Chicharro JL, Hoyos J, Lucía A. Effects of endurance training on the isocapnic buffering and hypocapnic hyperventilation phases in professional cyclists. British journal of sports medicine. 2000;34(6):450-5.

3. Algul S, Ozcelik O, Yilmaz B. Evaluation of relationship between aerobic fitness level and range of isocapnic buffering periods during incremental exercise test. Cellular and molecular biology. 2017;63(3):78-82.

4. Berti Zanella P, Donner Alves F, Guerini de Souza C. Effects of beta-alanine supplementation on performance and muscle fatigue in athletes and non-athletes of different sports: a systematic review. The Journal of sports medicine and physical fitness. 2017;57(9):113241.
5. Rosas F, Ramírez-Campillo R, Martínez C, Caniuqueo A, Cañas-Jamet R, McCrudden E, et al. Effects of Plyometric Training and Beta-Alanine Supplementation on Maximal-Intensity Exercise and Endurance in Female Soccer Players. Journal of human kinetics. 2017;58(1):99-109.

6. Saunders B, V DESP, LF DEO, V DAES, RP DAS, Riani L, et al. Twenty-four Weeks of beta-Alanine Supplementation on Carnosine Content, Related Genes, and Exercise. Medicine and science in sports and exercise. 2017;49(5):896-906.

7. Brisola GM, Artioli GG, Papoti M, Zagatto AM. Effects of Four Weeks of beta-Alanine Supplementation on Repeated Sprint Ability in Water Polo Players. PloS one. 2016;11(12):e0167968.

8. Jones RL, Barnett CT, Davidson J, Maritza B, Fraser WD, Harris R, et al. beta-alanine supplementation improves in-vivo fresh and fatigued skeletal muscle relaxation speed. Eur J Appl Physiol. 2017;117(5):86779.

9. Claus GM, Redkva PE, Brisola GMP, Malta ES, de Araujo Bonetti de Poli R, Miyagi WE, et al. BetaAlanine Supplementation Improves Throwing Velocities in Repeated Sprint Ability and 200-m Swimming Performance in Young Water Polo Players. Pediatric exercise science. 2017;29(2):203-12.

10. Sale C, Saunders B, Harris RC. Effect of beta-alanine supplementation on muscle carnosine concentrations and exercise performance. Amino acids. 2010;39(2):321-33.

11. JAMES RM, COOPER SB, ROBERTSON J, MARTIN D, HARRIS RC, SALE C. Effect of $\beta$-alanine supplementation on $20 \mathrm{~km}$ cycling time trial performance. Revista Brasileira de Educação Física e Esporte. 2014;28(3):395-403.

12. Kresta JY, Oliver J, Jagim A, Kreider R, Fluckey J, Reichman S, et al. Effects of 28 days of beta-alanine and creatine monohydrate supplementation on muscle carnosine, body composition and exercise performance in recreationally active females. Journal of the International Society of Sports Nutrition. 2012;9(Suppl 1):P17.

13. Glenn JM, Smith K, Moyen NE, Binns A, Gray M. Effects of acute beta-alanine supplementation on anaerobic performance in trained female cyclists. Journal of nutritional science and vitaminology. 2015;61(2):161-6.

14. Harris RC, Tallon M, Dunnett M, Boobis L, Coakley J, Kim HJ, et al. The absorption of orally supplied $\beta$ alanine and its effect on muscle carnosine synthesis in human vastus lateralis. Amino acids. 2006;30(3):27989.

15. Trexler ET, Smith-Ryan AE, Stout JR, Hoffman JR, Wilborn CD, Sale C, et al. International society of sports nutrition position stand: Beta-Alanine. Journal of the International Society of Sports Nutrition. 2015;12(1):30. 
16. Sale C, Artioli GG, Gualano B, Saunders B, Hobson RM, Harris RC. Carnosine: from exercise performance to health. Amino Acids. 2013;44(6):1477-91.

17. Dunnett M, Harris RC, Soliman MZ, Suwar AAS. Carnosine, anserine and taurine contents in individual fibres from the middle gluteal muscle of the camel. Research in Veterinary Science. 1997;62(3):213-6.

18. Derave W, Everaert I, Beeckman S, Baguet A. Muscle carnosine metabolism and $\beta$-alanine supplementation in relation to exercise and training. Sports medicine. 2010;40(3):247-63.
19. Saunders B, Elliott-Sale K, Artioli GG, Swinton PA, Dolan E, Roschel H, et al. $\beta$-alanine supplementation to improve exercise capacity and performance: a systematic review and meta-analysis. Br J Sports Med. 2016:bjsports-2016-096396.

20. Wilson JM, Wilson GJ, Zourdos MC, Smith AE, Stout JR. Beta-alanine supplementation improves aerobic and anaerobic indices of performance. Strength \& Conditioning Journal. 2010;32(1):71-8. 